\title{
Characteristics of Stimulation of $\mathrm{H}^{+}$Transport
}

\section{by Aldosterone in Turtle Urinary Bladder}

\author{
Qais Al-Awqati, Laurence H. Norby, Allan Mueller, and \\ Philip R. STEINMETZ \\ From the Department of Internal Medicine, University of Iowa College of \\ Medicine, Iowa City, lowa 52242
}

A B S T R A C T Aldosterone stimulates not only $\mathrm{Na}^{+} \mathrm{ab}-$ sorption but also urinary acidification. In this investigation the effects of aldosterone on $\mathrm{H}^{+}$transport are examined in vitro in turtle bladder, a urinary membrane in which several of the factors controlling $\mathrm{H}^{+}$transport have been defined. $\mathrm{H}^{+}$transport was increased in bladder halves exposed to aldosterone compared to control halves. Stimulation of $\mathrm{H}^{+}$secretion was observed as early as $1 \mathrm{~h}$ after addition of aldosterone and occurred before that of $\mathrm{Na}^{+}$transport. In bladders depleted of endogenous substrate addition of glucose increased $\mathrm{H}^{+}$ transport more in aldosterone-treated halves (10.0 \pm 1.3 $\mathrm{nmol} / \mathrm{min}$ ) than in control halves $(6.8 \pm 2.3)$. Addition of pyruvate failed to increase $\mathrm{H}^{+}$transport $(-0.3 \pm 0.7)$ in control halves but caused significant increments $(2.4 \pm 0.5)$ in aldosterone-treated halves. In aldosteronetreated bladders glucose caused larger increments (16.5 $\pm 2.7)$ in $\mathrm{H}^{+}$transport than pyruvate $(9.3 \pm 2.0)$ when halves of the same bladders were compared. $\mathrm{Na}^{+}$transport, however, was equally increased by the two substrates. Despite the differences in time course and substrate requirements between the stimulation of $\mathrm{H}^{+}$and $\mathrm{Na}^{+}$transport, both increases were abolished by actinomycin-D.

To examine the effect of aldosterone on the force of the $\mathrm{H}^{+}$pump, protonmotive force, the $\mathrm{pH}$ gradient that would nullify the transport rate was determined with and without aldosterone. Aldosterone did not alter protonmotive force but significantly increased the slope of the $\mathrm{H}^{+}$transport rate on the applied $\mathrm{pH}$ gradient. It

This work was presented in parts before the Midwestern Section of the American Federation for Clinical Research on 1 November 1974, Chicago, Ill., and before the National Meeting of the American Federation for Clinical Research on 4 May, 1975, Atlantic City, N. J.

Received for publication 29 September 1975 and in revised form 11 March 1976. is concluded that aldosterone stimulates $\mathrm{H}^{+}$transport independently of $\mathrm{Na}^{+}$transport. It increases the responsiveness of the transport rate to glucose and to a lesser extent pyruvate, an effect probably secondary to the increased transport rate. Equivalent circuit analysis indicates that aldosterone facilitates the flow of protons through the active transport pathway but does not increase the force of the pump.

\section{INTRODUCTION}

Several lines of evidence indicate that aldosterone not only stimulates the renal absorption of sodium but also the process of urinary acidification. To which extent the increased acidification is a function of accelerated sodium absorption remains to be determined. At least some studies suggest that acidification may be stimulated independently of sodium transport. Lifschitz et al. (1) provided some evidence in the dog that renal $\mathrm{H}^{+}$secretion is stimulated by a pathway that does not involve DNA-dependent synthesis of RNA. Ludens and Fanestil (2) reported that aldosterone increased the rate of acidification in the urinary bladder of the Colombian toad, as judged from the reversed short-circuit current after inhibition of sodium transport; they did not attempt, however, to explore the transport step in acidification that was stimulated by the hormone.

Since turtle urinary bladder responds to aldosterone (3) and is capable of urinary acidification under conditions that permit close examination of the transport components (4), this preparation was selected for a study of the mode of action of aldosterone on the process of acidification.

The studies indicate that aldosterone stimulates $\mathrm{H}^{+}$ secretion directly and that this stimulation precedes that of $\mathrm{Na}^{+}$transport. The stimulatory effect is markedly enhanced by the presence of substrates. Analysis of the stimulation of $\mathrm{H}^{+}$transport by means of an equivalent 
TABLE I

Stimulation of $J_{H}$ by Aldosterone

\begin{tabular}{|c|c|c|c|}
\hline & \multicolumn{3}{|c|}{$J_{\mathrm{H}, n m o l} / \min$} \\
\hline & $o$ & $2 h$ & $\Delta \pm S E$ \\
\hline \multicolumn{4}{|l|}{ Fresh } \\
\hline Aldosterone & 3.8 & 6.8 & $3.0 \pm 0.5$ \\
\hline Control & 4.2 & 5.2 & $1.0 \pm 0.5$ \\
\hline \multicolumn{4}{|l|}{ Depleted } \\
\hline Aldosterone & 4.9 & 5.8 & $+0.9 \pm 0.3$ \\
\hline Control & 4.9 & 4.3 & $-0.6 \pm 0.2$ \\
\hline
\end{tabular}

Paired hemibladders were exposed to $0.5 \mu \mathrm{M}$ aldosterone or diluent (control), either after mounting (fresh; $n=7$ ) or after $18 \mathrm{~h}$ of incubation in the absence of exogenous substrate (depleted; $n=17$ ). The gassing mixture was $\mathrm{CO}_{2}$-free air.

circuit model indicates that aldosterone increases the conductance in the active transport pathway and not the force of the pump. The increased conductance in this analysis would be consistent with the formation of new pump sites, an increase in the accessibility of existing pump sites or with other factors facilitating the flow of protons at a site close to the pump.

\section{METHODS}

Hemibladders of fresh water turtles, Pseudemys scripta, obtained from Mogul Ed, Oshkosh, Wis., were mounted in pairs of Lucite chambers so that one half served as control for the other which was exposed to aldosterone. The turtles were soaked for $24-48 \mathrm{~h}$ in $0.6 \% \mathrm{NaCl}$ to reduce endogenous mineralo-corticoid production. The experiments were carried out in the short-circuited state, and the rate of $\mathrm{H}^{+}$secretion was measured by the $\mathrm{pH}$ stat method as described previously (5). The rate of $\mathrm{Na}^{+}$transport was estimated as the sum of the short-circuit current and the rate of $\mathrm{H}^{+}$transport. In one series of experiments (Table

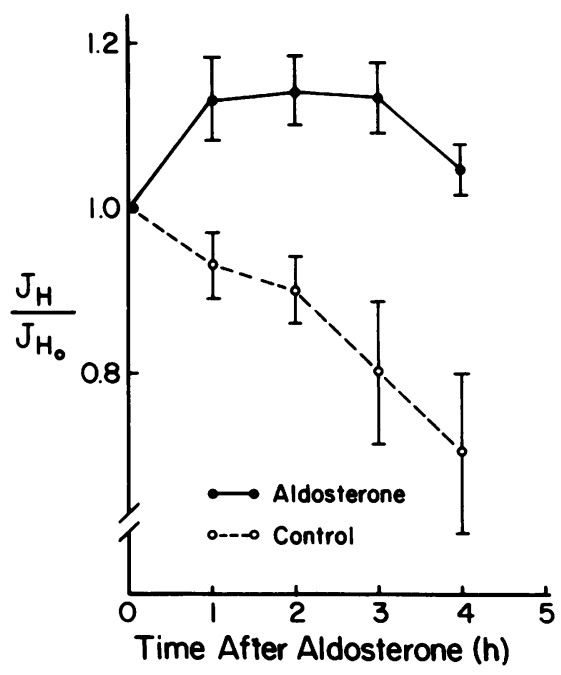

Figure 1 Time course of stimulation of $\mathrm{H}^{+}$secretion by aldosterone in seven substrate-depleted bladders.
VIII) carried out in bladders exposed to $0.5 \mathrm{mM}$ ouabain, the rate of $\mathrm{H}^{+}$transport was considered to be equal to the short-circuit current. The evidence for this equality has recently been reviewed (4). For the purposes of this study a series of eight experiments was carried out in the presence of $1 \% \mathrm{CO}_{2}$ and $0.5 \mathrm{mM}$ ouabain in the serosal solution; a plot of the $\mathrm{pH}$ stat rate against the simultaneously determined short-circuit current yielded a value of $1.01 \pm 0.01$ for the least-squares line.

The Ringer's solution used in these studies contained in mmol per liter: $\mathrm{Na}, 115: \mathrm{K}, 3.5 ; \mathrm{Ca}, 1.8 ; \mathrm{Cl}, 119.7: \mathrm{HPO}_{4}$ 0.3 ; the $\mathrm{pH}$ was 7.4 , and the gas phase was $\mathrm{CO}_{2}$-free air unless specified otherwise. D-aldosterone (Sigma Chemical Co., St. Louis, Mo.) was added in a final concentration of $0.5 \mu \mathrm{M}$ to the serosal side only. Similarly, the substrates, glucose and pyruvate were added to the serosal side in a final concentration of $5 \mathrm{mM}$ in the substrate experiments. Iil all experiments two hemibladders from the same turtle were used in identical chambers with an exposed membrane area of $8 \mathrm{~cm}^{2}$. Aldosterone was added in $50 \mu \mathrm{l}$ of methanol to the experimental halves, and $50 \mu \mathrm{l}$ of methanol was added to the control hemibladders. Statistical analysis was carried out by the paired $t$-test, and differences were considered significant at $P<0.05$. Results are expressed as means $\pm S E M$ for an area of $8 \mathrm{~cm}^{2}$.

\section{RESULTS}

(a) Rate limiting factors for $\mathrm{H}^{+}$secretion $\left(J_{H}\right)$. Before examining the effects of aldosterone on acidification the rate limiting factors for $J_{\mathbf{H}}$ must be considered. They are the electrochemical gradient for $\mathrm{H}^{+}$across the epithelium (6), the presence of $\mathrm{CO}_{2}(7)$, and the availability of metabolic fuels.

Metabolic fuel becomes limiting only in substrate-depleted bladders. In such bladders $\mathrm{CO}_{2}$ is no longer rate limiting in the absence of exogenous substrate as is shown in the following experiments. In five bladders that had been depleted of substrate for at least $18 \mathrm{~h} J_{\mathrm{H}}$ was $3.57 \mathrm{nmol} / \mathrm{min}$ when the gas phase was $\mathrm{CO}_{2}$-free air. After changing the gas phase to $1 \% \mathrm{CO}_{2}$ in air, $J_{\mathrm{H}}$ was $3.53 \mathrm{nmol} / \mathrm{min}$; the difference of $0.04 \pm 0.94 \mathrm{nmol} /$ min was not significant. Subsequent addition of $5 \mathrm{mM}$ glucose to the serosal solution increased $J_{\mathrm{H}}$ by $4.00 \pm$ $1.48 \mathrm{nmol} / \mathrm{min}(P<0.05)$.

If, on the other hand, glucose is added before $\mathrm{CO}_{2}$ is made available, $J_{\mathbf{H}}$ is increased, and an additional increment results when $\mathrm{CO}_{2}$ is added (see control experiments of Tables II and VII).

In substrate-depleted bladders, therefore, the secretion rate of $\mathrm{H}^{+}$is limited by the availability of metabolic fuel rather than $\mathrm{CO}_{2}$. An opposing electrochemical gradient, however, will reduce $J_{\mathrm{H}}$ under all circumstances.

(b) Stimulation of $\mathrm{H}^{+}$secretion by aldosterone. The effects of aldosterone on $J_{\mathbf{H}}$ were examined in urinary bladders of water turtles that had been kept in dilute saline to suppress the activity of endogenous mineralocorticoid hormone. In Table I, $J_{\mathrm{H}}$ is compared in hemibladders exposed to $0.5 \mu \mathrm{M}$ aldosterone and control halves of the same bladders in two series of experi- 
ments : in fresh bladders of turtles that had been quickly pithed to minimize the secretion of endogenous hormone and in bladders that had been depleted of substrate as well as endogenous hormone by overnight incubation in Ussing chambers. In both groups of experiments, $J_{\mathbf{H}}$ was increased $2 \mathrm{~h}$ after exposure to aldosterone, and the observed differences between the aldosterone-treated bladders and the control halves were significant. In the substrate-depleted bladders, however, the control rates of $\mathrm{H}^{+}$secretion and the magnitude of stimulation by aldosterone were variable. As will be shown later (Table II), the stimulation of $J_{\mathbf{H}}$ by aldosterone is increased by addition of substrate, especially glucose.

The time course of the effect of aldosterone in substrate-depleted bladders is given in Fig. 1. Initial $J_{\mathbf{H}}$ was $6.1 \pm 1.0 \mathrm{nmol} / \mathrm{min}$ in seven test bladders and $5.5 \pm$ 1.0 in the control halves. The ratios of $J_{\mathrm{H}}$ at the 1st, 2nd, 3rd, and 4th $\mathrm{h}$ over the initial rate, $J_{\mathrm{H}_{\mathrm{n}}}$, are presented. $J_{\mathrm{B}}$ in the control halves (dashed line) declined slowly with time. In contrast, $J_{\mathrm{B}}$ increased in the aldosterone-treated hemibladders. The ratio of $J_{\mathbf{H}}$ over $J_{\mathbf{H}_{0}}$ was significantly different from that in the controls as early as $1 \mathrm{~h}$ after aldosterone addition.

(c) The effect on $J_{\mathrm{B}}$ of substrates and stimulation by aldosterone. In bladders depleted of endogenous substrate $J_{\mathbf{H}}$ is increased by the addition of glucose. Table II shows that the addition of $5 \mathrm{mM}$ glucose caused a marked increase in $J_{\mathbf{H}}$ from 4.3 to $11.2 \mathrm{nmol} / \mathrm{min}$. It is of interest (lower half of Table II) that pyruvate failed to stimulate $J_{\mathrm{H}}$ in the absence of aldosterone. All measurements of $J_{\mathbf{H}}$ were made in the absence of exogenous $\mathrm{CO}_{3}$ by the $\mathrm{pH}$ stat method.

In aldosterone-treated bladders a synergistic effect is demonstrated when glucose is added $4 \mathrm{~h}$ after the addition of aldosterone. Aldosterone plus glucose caused a large increment in $J_{\mathbf{H}}$ that was significantly greater than that caused by glucose alone. Pyruvate, which failed to stimulate $J_{\mathbf{H}}$ in the control bladders, also caused a significant increment in the aldosterone-treated bladders.

To obtain a better comparison of the effects of glucose and pyruvate, paired hemibladders were incubated overnight in media containing $5 \times 10^{-7} \mathrm{M}$ aldosterone and no substrate. Since changes in sodium transport may affect $J_{\mathrm{H}}$ via changes in the availability of $\mathrm{CO}_{2}$, the serosal gas phase contained $1 \% \mathrm{CO}_{2}$. The stimulation of $J_{\mathbf{H}}$ by glucose and pyruvate in halves of the same bladders is shown in Table III. Glucose caused an increment of $16.5 \pm 2.7 \mathrm{nmol} / \mathrm{min}$, whereas pyruvate caused a significantly smaller increment of $9.3 \pm 2.0 \mathrm{nmol} / \mathrm{min}$.

The results of Tables II and III indicate that aldosterone increases the responsiveness of the transport system for $\mathrm{H}^{+}$to substrate and that under the experimental conditions used glucose stimulates $J_{\mathbf{H}}$ more than equimolar quantities of pyruvate.
TABLE II

Effect of Aldosterone and Exogenous Substrates on $J_{H}$

\begin{tabular}{lccr}
\hline & \multicolumn{3}{c}{$J_{\mathrm{H}, n m o l / m i n}$} \\
& No & Glucose & $\Delta$ Substrate \\
& substrate & & \\
Aldosterone & 5.8 & 15.8 & $10.0 \pm 1.3$ \\
Control & 4.3 & 11.2 & $6.8 \pm 2.3$ \\
$\Delta$ (A-C) & & & $3.2 \pm 0.8$ \\
& No & Pyruvate & Substrate \\
& substrate & & \\
Aldosterone & 3.3 & 5.7 & $2.4 \pm 0.5$ \\
Control & 3.4 & 3.1 & $-0.3 \pm 0.7$ \\
$\Delta$ (A-C) & & & $2.7 \pm 0.8$ \\
\hline
\end{tabular}

Paired hemibladders depleted of endogenous substrate were exposed to $0.5 \mu \mathrm{M}$ aldosterone or diluent (control) for $4 \mathrm{~h}$. At this time $J_{\mathrm{H}}$ was measured (no substrate). Glucose $(n=7)$ or pyruvate $(n=5)$ was then added to the serosal side, and the maximal values for $J_{\mathbf{H}}$ over the next $2 \mathrm{~h}$ were recorded. The gassing mixture was $\mathrm{CO}_{2}$-free air.

The effect of aldosterone on $J_{\mathbf{H}}$ was also examined 2-3 $\mathrm{h}$ after addition of either glucose or pyruvate to substrate-depleted bladders. Aldosterone caused a sustained increase in $\mathrm{H}^{+}$secretion in the presence of glucose $(n=6)$, but failed to bring about a consistent increase in the presence of pyruvate $(n=6)$. In both sets of experiments $J_{\mathrm{Na}}$ was markedly increased in the aldosterone-treated bladder halves compared to the control halves.

These results suggest that the stimulation of $\mathrm{H}^{+}$secretion is best supported by glucose as the substrate. Although pyruvate consistently enhanced the stimulation of $J_{\mathrm{Na}}$, its effects on the stimulation of $J_{\mathbf{H}}$ were variable.

(d) Comparison of stimulation of $J_{\mathrm{H}}$ and $J_{\mathrm{Na}}$. Fig. 2 shows the effect of aldosterone on $J_{\mathrm{Na}}$, estimated as the sum of the short-circuit current and the current equivalent of $J_{\mathbf{H}}$, in the seven substrate-depleted bladders of Fig. 1. In the hemibladders exposed to aldosterone, $J_{\mathrm{Na}}$ was increased compared to the control halves. In contrast to the increase in $J_{\mathbf{H}}$ (Fig. 1), which was signifi-

\section{TABLE III}

Comparison of the Effects of Glucose and Pyruvate on $J_{H}$ in the Presence of Aldosterone in Paired Hemibladders

\begin{tabular}{llcr}
\hline & \multicolumn{3}{c}{$J_{\mathbf{H}, n \text { mol } / \text { min }}$} \\
\hline Substrate & 0 & + & $\Delta \pm \mathrm{SE}$ \\
Glucose & 6.0 & 22.5 & $16.5 \pm 2.7$ \\
Pyruvate & 5.5 & 14.8 & $9.3 \pm 2.0$
\end{tabular}

Six paired hemibladders were incubated for 18-20 $\mathrm{h}$ in media containing $0.5 \mu \mathrm{M}$ aldosterone but no exogenous substrate. $J_{\mathbf{H}}$ was then measured, and one substrate was added to each hemibladder. The maximal values over the next $2 \mathrm{~h}$ were recorded. The serosal gas phase was $1 \% \mathrm{CO}_{2}$ in air.

Stimulation of $\mathrm{H}^{+}$Transport by Aldosterone 


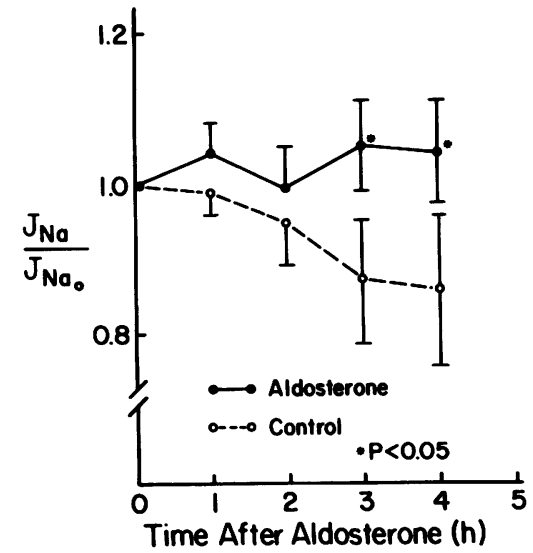

FIgURE 2 Time course of stimulation of $J_{\mathrm{Na}}$ in the seven bladders of Fig. 1.

cant after $1 \mathrm{~h}$ of aldosterone, the increase in $J_{\mathrm{Na}}$ became significant only after $3 \mathrm{~h}^{1}{ }^{1}$ This result is comparable to observations by Lefèvre (3), who reported that the short-circuit current in turtle bladder was increased by aldosterone after an interval of $3 \mathrm{~h}$. She found that the maximal stimulation occurred at about $7 \mathrm{~h}$ in substratedepleted bladders.

The stimulation of $J_{\mathrm{Na}}$ by aldosterone was enhanced in depleted bladders by the addition of substrate. In the experiments of Table II both glucose and pyruvate increased the difference in $J_{\mathrm{Na}}$ between aldosterone-treated and control halves. In both, $J_{\mathrm{Na}}$ was approximately doubled in the presence of aldosterone. Table IV corresponds to Table III and compares the increments in $J_{\mathrm{Na}}$ caused by equimolar amounts of glucose and pyruvate. The increments in $J_{\mathrm{Na}}$ were comparable with the two substrates whereas the increments in $J_{\mathbf{H}}$ (Table III) had been significantly larger with glucose.

As indicated above, addition of aldosterone $2-3 \mathrm{~h}$ after substrate addition to depleted bladders caused marked stimulation of $J_{\mathrm{Na}}$ in the presence of either glucose or pyruvate. $J_{\mathrm{Na}}$ was still increasing during the 6 th-h of observation. In contrast, $J_{\mathbf{B}}$ was stimulated only in the presence of glucose and reached an apparent steady level between 4 and $6 \mathrm{~h}$.

These results suggest that the stimulation of $J_{\mathbf{B}}$ precedes that of $J_{\mathrm{Na}}$ : first, in substrate-depleted bladders stimulation of $J_{\mathrm{H}}$ began before that of $J_{\mathrm{Na}}$; and second, in the presence of glucose $J_{\mathrm{B}}$ reached a steady level be-

${ }^{1}$ To examine the independence of the stimulation of $J_{H}$ from that of $J_{\mathrm{Na}}$ with respect to time the data of Fig. 1 and 2 were subjected to multivariate analysis of variance. According to this analysis $J_{\mathrm{H}}$ is stimulated significantly $(P<$ $0.05)$ while $J_{\mathrm{Na}}$ was not $(P>0.05)$ over the 4 -h time period. More importantly, there was no significant interaction between $J_{\mathrm{H}}$ and $J_{\mathrm{Na}}$. We are indebted to Dr. J. Kondo, Biostatistics Section, Department of Preventive Medicine, University of Iowa, for performing this analysis.
TABLE IV

Comparison of the Effects of Glucose and Pyruvate on $J_{N a}$ in the Presence of Aldosterone in Paired Hemibladders

\begin{tabular}{lccc}
\hline & \multicolumn{3}{c}{$J_{\mathrm{Na}, \mu A}$} \\
\hline Substrate & 0 & + & $\Delta \pm \mathrm{SE}$ \\
Glucose & 87 & 145 & $58 \pm 9$ \\
Pyruvate & 64 & 125 & $61 \pm 18$ \\
\hline
\end{tabular}

Six paired hemibladders were incubated for 18-20 h in media containing $0.5 \mu \mathrm{M}$ aldosterone but no exogenous substrate. $J_{\mathrm{Na}}$ was then measured, and one substrate was added to each hemibladder. The serosal gas phase was $1 \% \mathrm{CO}_{2}$ in air.

tween 4 and $6 \mathrm{~h}$ at a time that $J_{\mathrm{Na}}$ was still increasing. Under comparable conditions Lefèvre (3) observed the maximal increase in short-circuit current at $13 \mathrm{~h}$. Aside from the difference in time course between the stimulation of the two transport systems, there is a difference in the substrate requirements, $J_{\mathbf{B}}$ being best supported by glucose and $J_{\mathrm{Na}}$ by either glucose or pyruvate.

To examine whether the stimulation of the two transport systems might have different mechanisms and whether these might be dissociated by an inhibitor of DNA-dependent RNA synthesis, the effects of aldosterone were studied in bladders pretreated with actinomycin-D. Table $\mathrm{V}$ shows that substrate-depleted bladders exposed to actinomycin-D in a final concentration of $2 \mu \mathrm{g} / \mathrm{ml}$ in the presence of $5 \mathrm{mM}$ glucose in the media and $1 \% \mathrm{CO}_{3}$ in the gas phase fail to respond to aldosterone. Stimulation of neither $J_{\mathrm{B}}$ nor $J_{\mathrm{Na}}$ could be demonstrated. $J_{\mathrm{H}}$ and $J_{\mathrm{Na}}$ declined with time in both control and aldosterone-treated hemibladders. There was no significant difference between control and aldosterone bladders. Since the stimulation of $J_{\mathrm{Na}}$ and $J_{\mathrm{B}}$ by aldosterone was demonstrated in a consistent manner in the presence of glucose, these results are consistent with the

TABLE V

Effect of Aldosterone on $J_{H}$ and $J_{N a}$ in Paired Hemibladders Pretreated with Actinomycin-D

\begin{tabular}{lrrrrr}
\hline Time & \multicolumn{1}{c}{1} & \multicolumn{1}{c}{2} & 3 & \multicolumn{1}{c}{4} \\
\hline $\begin{array}{l}J_{\text {II, nmol } / \mathrm{min}} \\
\text { Aldosterone }\end{array}$ & & & & & \\
& 14.8 & 12.8 & 10.0 & 7.9 & 7.1 \\
Control & \pm 3.2 & \pm 2.2 & \pm 1.4 & \pm 1.9 & \pm 2.0 \\
& 14.2 & 13.5 & 11.0 & 10.1 & 10.2 \\
$J_{\text {Na, } \mu \text { A }}$ & \pm 4.3 & \pm 4.1 & \pm 4.1 & \pm 4.5 & \pm 4.4 \\
Aldosterone & & & & & \\
& 196 & 164 & 123 & 99 & 85 \\
Control & \pm 70 & \pm 150 & \pm 36 & \pm 24 & \pm 17 \\
& 96 & 91 & 81 & 78 & 78 \\
& \pm 38 & \pm 40 & \pm 39 & \pm 42 & \pm 44 \\
\hline
\end{tabular}

$2 \mathrm{~h}$ before the addition of aldosterone or diluent the bladders $(n=5)$ were exposed to actinomycin-D $(2 \mu \mathrm{g} / \mathrm{ml})$ and $5 \mathrm{mM}$ glucose. The serosal gas phase was $1 \% \mathrm{CO}_{2}$ in air. 
interpretation that both processes of stimulation depend on DNA-dependent RNA synthesis.

(e) Effect of substrate at two different levels of $J_{\mathbf{H}}$. The enhanced responsiveness of the transport rate to metabolic substrates in the presence of aldosterone could be a reflection of the increased transport rate per se rather than of an effect of aldosterone on metabolism. To examine this point the effects of glucose on $J_{\mathbf{B}}$ were studied at two secretion rates in depleted bladders in the absence of aldosterone. The rate of transport was varied by lowering luminal $\mathrm{pH}$ from 7.0 to 6.0 . It had been previously shown (6) that luminal acidification decreases the rate of active $\mathrm{H}^{+}$transport. Table VI shows that serosal addition of glucose caused an increment in $J_{\mathrm{H}}$ that was almost three times as great at the higher rate of transport (luminal $\mathrm{pH}=7$ ) as at the low rate of transport (luminal $\mathrm{pH}=6$ ). The transport rate per se, therefore, appears to be a determinant of the extent to which substrates will increase $J_{\mathrm{H}}$.

(f) Stimulation of $J_{\mathrm{H}}$ by aldosterone is not mediated by $\mathrm{CO}_{2}$. Aldosterone could stimulate $J_{\mathbf{H}}$ either directly or by increasing the production of metabolic $\mathrm{CO}_{2}$ through a mechanism unrelated to transport. The latter explanation is unlikely since the experiments of section (a) have shown that exogenous $\mathrm{CO}_{2}$ fails to increase $J_{\mathrm{H}}$ in substrate-depleted bladders. Hence, even if aldosterone increased the $\mathrm{CO}_{2}$ production by the tissue, the $\mathrm{H}^{+}$transport system would not have responded. To demonstrate further that the increase in $J_{\mathbf{H}}$ caused by aldosterone was not mediated through increased $\mathrm{CO}_{2}$ production, the effects of addition of exogenous $\mathrm{CO}_{2}$ were explored in aldosterone-treated and control hemibladders. Table VII shows that $\mathrm{H}^{+}$secretion was greater in the aldosterone-treated hemibladders before addition of $\mathrm{CO}_{2}$. Addition of $\mathrm{CO}_{2}$ caused a larger increment in the aldosterone-treated hemibladders than in the control halves. Both rates were approximately doubled. These results indicate that aldosterone increases $J_{\mathrm{H}}$ by some mechanism other than an increase in $\mathrm{Pco}_{2}$.

TABLE VI

Effect of Glucose at Two Levels of $J_{H}$

\begin{tabular}{lccr}
\hline & \multicolumn{3}{c}{$J_{\mathrm{H}, n \text { mol } / \text { min }}$} \\
\hline & No & Glucose & \multicolumn{1}{c}{$\Delta$} \\
& substrate & & \\
Luminal $\mathrm{pH}=6.0$ & 12.8 & 17.2 & $4.4 \pm 1.6$ \\
Luminal $\mathrm{pH}=7.0$ & 18.5 & 30.9 & $12.4 \pm 2.7$ \\
$\Delta$ & & & $8.0 \pm 2.2$ \\
\hline
\end{tabular}

$J_{\mathbf{H}}$ was measured in six substrate-depleted bladders in the absence of aldosterone at luminal $\mathrm{pH}=6$ and at $\mathrm{pH}=7$; the measurements were repeated after addition of glucose. Serosal $\mathrm{pH}$ was kept constant at 7.4. The gassing mixture was $1 \% \mathrm{CO}_{2}$.
TABLE VII

Effect of Exogenous $\mathrm{CO}_{2}$ on $J_{H}$

\begin{tabular}{lccc}
\hline & \multicolumn{3}{c}{$J_{\mathrm{H}, \mathrm{nmol} / \mathrm{min}}$} \\
\hline & $\mathrm{CO}_{2}$-free & $1 \% \mathrm{CO}_{2}$ & $\Delta$ \\
Aldosterone & 6.5 & 12.5 & $6.0 \pm 1.9$ \\
Control & 3.9 & 8.0 & $4.1 \pm 1.0$ \\
$\Delta$ (A-C) & & & $1.9 \pm 0.8$
\end{tabular}

$J_{\mathrm{H}}$ was measured in four substrate-depleted bladders $4 \mathrm{~h}$ after addition of pyruvate and $0.5 \mu \mathrm{M}$ aldosterone or diluent (control). The serosal gas phase was then changed from $\mathrm{CO}_{2}$-free air to $1 \% \mathrm{CO}_{2}$ in air.

(g) Effect of aldosterone on the force of the $H^{+}$ pump. To evaluate the site of action of aldosterone on $\mathrm{H}^{+}$transport, we will consider a general model of an energy converter in which metabolic energy is linked to a transport step. In such a model aldosterone could either facilitate the flow of protons through the transport system or alter the driving metabolic reaction in such a way that the transfer of chemical energy is promoted. It has been shown previously (6) that application of an unfavorable $\mathrm{pH}$ gradient across the bladder results in a decrease in $J_{\mathbf{H}}{ }^{2}$ Following Ussing and Zerahn (8), it can be argued that the magnitude of the gradient sufficient to nullify the transport rate is equivalent to the force of the $\mathrm{H}^{+}$pump (the protonmotive force, $[\mathrm{PMF}]$ ). ${ }^{3}$ Using a model of $\mathrm{H}^{+}$transport (see Discussion for details), it can be shown that the slope of $J_{\mathrm{H}}$ on the applied $\mathrm{pH}$ gradient gives the parameter that describes the ease with which protons flow through the system. ${ }^{4}$ The value of the PMF is a composite function which is determined, in part, by the free energy of the driving metabolic reaction. To determine these two parameters experiments were performed in paired hemibladders using the short-circuit current as the measure of $\mathrm{H}^{+}$transport. The luminal $\mathrm{pH}$ was lowered in steps in paired hemibladders in the presence of $1 \% \mathrm{CO}_{2}$ and 5 $\mathrm{mM}$ glucose in the media. The serosal $\mathrm{pH}$ was kept at 7.4 .

\footnotetext{
${ }^{2}$ Steinmetz and Lawson (6) showed that the passive transepithelial $\mathrm{H}^{+}$permeability is negligible over the range of spontaneous acidification. The decrease in $J_{\mathbf{H}}$ with opposing $\mathrm{H}^{+}$gradient, therefore, reflects a decrease in the forward flux of $\mathrm{H}^{+}$.

${ }^{3}$ Abbreviation used in this paper: $\mathrm{PMF}$, protonmotive force.

4 For this analysis it is assumed that the conductance of the other ions is not affected by lowering of the luminal $\mathrm{pH}$. Steinmetz and Lawson (6) observed that in ouabain-treated bladders (as were used for the experiments of Table VIII) the $\mathrm{Na}^{+}$conductance is not affected by luminal acidification over the range used. Likewise, luminal acidification had no effect on the permeabilities of $\mathrm{Cl}^{-}, \mathrm{Cs}^{+}$, and $\mathrm{K}^{+}$in shortcircuited control bladders (6).
} 

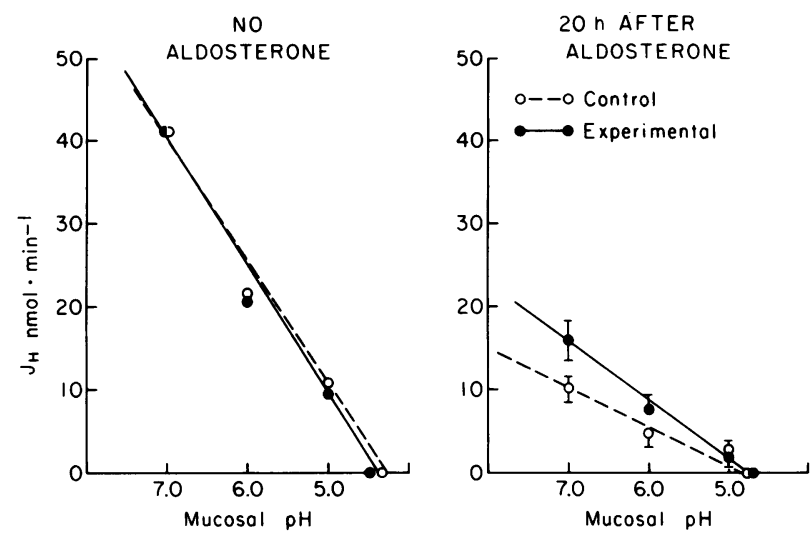

Figure 3 Failure of aldosterone to alter the force of the $\mathrm{H}^{+}$pump. In the left panel $J_{\mathrm{H}}$ was reduced to zero by lowering of mucosal $\mathrm{pH}$ before addition of aldosterone. The panel on the right shows the results of the same maneuver $20 \mathrm{~h}$ after addition of aldosterone or diluent (based on results of Table VIII).

Fig. 3 shows how $J_{\mathrm{H}}$ decreased with decreasing luminal $\mathrm{pH}$. The left panel demonstrates that $J_{\mathbf{B}}$ decreased in similar manner in both hemibladders before addition of aldosterone. The panel on the right gives the results $20 \mathrm{~h}$ after addition of aldosterone or diluent to the hemibladders. $J_{\mathbf{B}}$ was increased in the tissues exposed to aldosterone, but the luminal $\mathrm{pH}$ at which $J_{\mathbf{H}}$ became zero (PMF) was the same for both groups of hemibladders. The slope of $J_{\mathbf{H}}$ on the applied chemical gradient, therefore, was increased by aldosterone. The values for $J_{\mathrm{H}}, \mathrm{PMF}$, and the slope $\partial J_{\mathrm{B}} / \partial \Delta \mathrm{pH}$ are given in Table VIII for the 1st day on the left and after aldosterone on the right. Aldosterone caused no significant change in PMF while $J_{\mathbf{H}}$ and the slope were clearly increased.

The results suggest that aldosterone does not increase the force of the pump directly but increases $J_{\mathbf{H}}$ by increasing the conductance in series with the active trans- port pathway or by a thermodynamically equivalent mechanism.

\section{DISCUSSION}

The present study indicates that aldosterone stimulates $\mathrm{H}^{+}$secretion as well as $\mathrm{Na}^{+}$transport by the isolated turtle bladder. It confirms the observation by LeFèvre (3) that the response of sodium transport to aldosterone is slow in turtle bladder, and it supports the results obtained by Ludens and Fanestil (2) on urinary acidification by the Colombian toad bladder. Several characteristics of the stimulation of $\mathrm{H}^{+}$secretion in turtle bladder are defined. It is shown that $\mathrm{H}^{+}$secretion is stimulated independently of the stimulation of $\mathrm{Na}^{+}$transport and that stimulation is demonstrable in the presence as well as in the absence of the two known rate-limiting substrates for $\mathrm{H}^{+}$secretion: exogenous $\mathrm{CO}_{2}$ and metabolic substrates. Finally, the mode of action of aldosterone is analysed in an equivalent circuit model of $\mathrm{H}^{+}$transport.

Several lines of evidence indicate that the stimulation of $\mathrm{H}^{+}$secretion is independent of that of $\mathrm{Na}^{+}$transport. First of all, the stimulation of $\mathrm{H}^{+}$secretion precedes that of $\mathrm{Na}^{+}$transport by about $2 \mathrm{~h}$. Secondly, in aldosteronetreated bladders the stimulation of $\mathrm{H}^{+}$secretion has different substrate requirements than the stimulation of $\mathrm{Na}^{+}$transport. $\mathrm{H}^{+}$secretion was increased twice as much by addition of glucose as by addition of pyruvate, whereas $\mathrm{Na}^{+}$transport was increased to the same extent by these two substrates. Thirdly, $\mathrm{H}^{+}$secretion was stimulated by aldosterone in bladders in which $\mathrm{Na}^{+}$ transport was abolished by ouabain (Table VIII). Since aldosterone is thought to exert its effect on sodium transport through a process involving DNA-dependent RNA synthesis (9), it would be conceivable that the early stimulation of $\mathrm{H}^{+}$secretion would be mediated by some other mechanism. This possibility, in fact, was suggested by Lifschitz et al. (1) who observed that actinomycin-D inhibits the aldosterone-induced increase in

TABLE VIII

The Force of the $H^{+}$Pump before and after Addition of Aldosterone

\begin{tabular}{lcccccc}
\hline & \multicolumn{3}{c}{ Before addition } & \multicolumn{3}{c}{$20 \mathrm{~h}$ after addition } \\
\hline & $J_{H}$ & $P M F$ & $\partial J_{\mathrm{H}} / \partial \Delta \mathrm{pH}$ & $J_{H}$ & $P M F$ & $\partial J_{\mathrm{H}} / \partial \Delta \mathrm{pH}$ \\
Aldosterone & 41.2 & 3.00 & 15.9 & 16.0 & 2.75 & 6.9 \\
Control & 41.0 & 3.11 & 15.1 & 10.1 & 2.87 & 4.1 \\
$\Delta$ (A-C) & & & & 5.9 & -0.12 & 2.8 \\
& & & & \pm 2.2 & \pm 0.18 & \pm 0.6
\end{tabular}

$J_{\mathbf{H}}$ is expressed as $\mathrm{nmol} / \mathrm{min}$ and $\mathrm{PMF}$ as $\mathrm{pH}$ units. The results of the left panel were obtained when the bladder halves were fresh; the results of the right panel were obtained either after $20 \mathrm{~h}$ of exposure to aldosterone or after depletion of endogenous hormone (control). All experiments were carried out in the presence of $0.5 \mathrm{mM}$ ouabain, $5 \mathrm{mM}$ glucose, and $1 \% \mathrm{CO}_{2}$ in the gas phase. 
sodium absorption but not in $\mathrm{H}^{+}$secretion in the dog. In the isolated turtle bladder both the early stimulation of $\mathrm{H}^{+}$secretion and the late stimulation of $\mathrm{Na}^{+}$transport were abolished by actinomycin-D. The separate stimulation of $\mathrm{H}^{+}$secretion and $\mathrm{Na}^{+}$absorption and their specific substrate dependence could reflect the synthesis of two different proteins or merely inherent differences in the characteristics of the two transport systems.

The results of Tables II and III clearly indicate that the presence of aldosterone increases the responsiveness of substrate-depleted bladders to the addition of glucose or pyruvate. Both $\mathrm{H}^{+}$secretion and sodium transport showed this increased responsiveness, but for $\mathrm{H}^{+}$secretion glucose was preferred over pyruvate as a substrate. This synergism between aldosterone and substrate is well known for the sodium transport system in the toad bladder $(9,10)$. Its mechanism, however, remains only partially understood. Sharp and Leaf (10) have provided evidence that the stimulation of metabolism is secondary to stimulation of $\mathrm{Na}^{+}$transport, whereas Fanestil et al. (9) have suggested that aldosterone has a primary effect on the metabolic reactions coupled to sodium transport.

If the stimulation of $\mathrm{H}^{+}$transport by metabolic substrates is secondary to a primary acceleration of the transport step by aldosterone, then one should be able to demonstrate such a substrate effect following other maneuvers that primarily accelerate transport. Changes in the $\mathrm{pH}$ gradient against which $\mathrm{H}^{+}$secretion occurs alter the transport rate instantaneously (6). It was shown in Table VI that in depleted bladders not exposed to aldosterone the response of $J_{\mathrm{H}}$ to glucose addition was a function of the basal transport rate. The response was considerably greater at the higher basal transport rate observed at a mucosal $\mathrm{pH}$ of 7 than at the reduced rate at $\mathrm{pH} 6$. This apparent dependence of the substrate effect on the basal transport rate is consistent with the interpretation that the stimulation of metabolism by aldosterone is probably secondary to its effect on the transport system.

The secretion of $\mathrm{H}^{+}$by the turtle bladder may be outlined by the following working description (4): protons, perhaps originating from splitting of water molecules, are translocated across the luminal border of the epithelium in a process that requires the input of metabolic energy. The hydroxyl ions remaining are disposed of with the aid of cytoplasmic carbonic anhydrase by combining with $\mathrm{CO}_{2}$; the $\mathrm{HCO}_{3}^{-}$so formed then diffuses down an electrochemical gradient into the serosal side. By analogy with the sodium transport system $(8,11)$ this process can be represented by an equivalent circuit made up of a battery representing the proton pump, a resistance in series with the pump and a shunt resistance in parallel with the pump. The force of the pump, the
PMF, can be evaluated following Ussing and Zerahn (8), as the transepithelial gradient necessary to bring net transport to zero. It follows then that for a constant flow of current through the parallel limb, the series conductance is approximated by the slope of the $\mathrm{H}^{+}$ transport rate on the applied gradient." In evaluating these two parameters of the equivalent circuit, Table VIII shows that aldosterone does not change the PMF but significantly increases the conductance in the active pathway.

In this representation, what do the elements of the circuit represent? The PMF is considered to be a function of the chemical reaction that leads to charge separation. It includes a term that is equivalent to the free energy $(\Delta G)$ of the reaction that is tightly linked to transport. In many transport systems it is believed that ATP hydrolysis is an important "energy donor"; hence, the free energy available from ATP hydrolysis would be a determining factor in the value of the PMF. The PMF, however, depends not only on the free energy of the chemical reaction but also on its relation to the flow and translocation of protons through the system (12).

The conductance in the active transport pathway reflects the facility with which either protons or $\mathrm{OH}^{-}$ions flow from the site of dissociation. This extensive function also includes, in descriptive terms, the number of pump sites available for the dissociation reaction. The parallel conductance for $\mathrm{H}^{+}$in turtle bladder is low as judged from the studies of Steinmetz and Lawson (6) and from recent evidence (13).

Essig and Caplan (12) have given a formal description of this kind of analysis in terms of linear irreversible thermodynamics. The formalism requires that the flow of the transported ion species $\left(J_{\mathbf{H}}\right)$ and the flow of metabolism $\left(J_{r}\right)$ are coupled to the conjugate forces of the ion $\left(X_{\mathbf{H}}\right)$, and of metabolism ( $A$, the affinity of the driving chemical reaction i.e. the $\Delta \mathrm{G}$ noted above).

$$
\begin{aligned}
& J_{\mathrm{H}}=L_{\mathrm{H}} X_{\mathrm{H}}+L_{\mathrm{H} r} A \\
& J_{r}=L_{r \mathrm{H}} X_{\mathrm{H}}+L_{r} A
\end{aligned}
$$

where $L_{\mathrm{B}}$ and $L_{r}$ are "straight coefficients" relating the flow of one species to its driving force, and $L_{\mathbf{H r}}$ and $L_{\mathbf{r H}}$ are cross coefficients relating the flow of one species to the driving force of the other species. Over the $\mathrm{pH}$ range examined both $J_{\mathrm{H}}$ and $J_{r}{ }^{5}$ have been shown to be a linear function of the transepithelial $\mathrm{pH}$ gradient $(6$, $13,14)$. The two cross coefficients, following Onsager (15), are considered to be equal. The PMF in this

\footnotetext{
${ }^{5} J_{r}$ was measured continuously as the rate of ${ }^{14} \mathrm{CO}_{2}$ production from [U- ${ }^{14} \mathrm{C}$ ] glucose in ouabain-treated bladders $(13,14)$. Because of the linearity of $J_{r}$ and $X_{\mathbf{H}}$, the affinity may be considered constant during the period of experimental observation.
} 
analysis is $\left(X_{H}\right) J_{H}=0$ and is equal to

$$
\left(X_{\mathbf{H}}\right) J_{\mathbf{B}=0}=\left[L_{r \mathbf{H}} / L_{\mathbf{H}}\right] A
$$

and

$$
L_{\mathbf{H}}=\left[\partial J_{\mathbf{H}} / \partial X_{\mathbf{H}}\right]_{\mathbf{A}}
$$

Since the affinity is probably constant during the period of the experiment, $L_{H}$ is equivalent to the slope shown in Fig. 3. The constancy of the PMF could reflect a constant affinity or, alternatively, an increased affinity balanced by a decrease in the fraction $L_{\mathbf{r}} / L_{\mathbf{H}}$. Recently, Saito et al. (16) have shown in the frog skin that the affinity may indeed increase after prolonged incubation with aldosterone.

It follows from this analysis that aldosterone increases the conductance of protons through the active pathway and not the PMF in the system. As discussed, the increased active conductance could represent a number of changes in the overall transport operation of the system. Among the more attractive possibilities are the formation of new pump sites or a structural change in the luminal membrane that would provide access to an increased number of existing pump sites. These changes would be mediated one way or another by the synthesis of new proteins (17). Alternatively, the increased conductance could be a manifestation of a change in the physical state of the membrane that would increase the mobility of protons through the active pathway. Recently, Goodman et al. (18) have provided evidence that aldosterone changes the lipid composition of the membrane in a way that would increase its "fluidity."

\section{ACKNOWLEDGMENTS}

This paper was supported by grant AM 17568 from the U. S. Public Health Service and, in part, by funds from the Iowa Heart Association.

\section{REFERENCES}

1. Lifschitz, M. D., R. W. Schrier, and I. S. Edelman. 1973. Effect of actinomycin-D on aldosterone-mediated changes in electrolyte excretion. Am. J. Physiol. 224: 376-380.

2. Ludens, J. H., and D. D. Fanestil. 1974. Aldosterone stimulation of acidification of urine by isolated urinary bladder of the Colombian toad. Am. J. Physiol. 226: 1321-1326.
3. LeFevre, M. E. 1973. Effects of aldosterone on the isolated substrate-depleted turtle bladder. Am. J. Physiol. 225 : 1252-1256.

4. Steinmetz, P. R. 1974. Cellular mechanisms of urinary acidification. Physiol. Rev. 54: 890-956.

5. Steinmetz, P. R. 1967. Characteristics of hydrogen ion transport in urinary bladder of water turtle. J. Clin. Invest. 46: 1531-1540.

6. Steinmetz, P. R., and L. R. Lawson. 1971. Effect of luminal $\mathrm{pH}$ on ion permeability and flows of $\mathrm{Na}^{+}$and $\mathrm{H}^{+}$ in turtle bladder. Am. J. Physiol. 220: 1573-1580.

7. Schwartz, J. H., and P. R. Steinmetz. 1971. $\mathrm{CO}_{2}$ requirements for $\mathrm{H}^{+}$secretion in the isolated turtle bladder. Am. J. Physiol. 220: 2051-2057.

8. Ussing, H. H., and K. Zerahn. 1951. Active transport of sodium as the source of electric current in the shortcircuited isolated frog skin. Acta. Physiol. Scand. 23: 110-127.

9. Fanestil, D. D., T. S. Herman, G. M. Fimognari, and I. S. Edelman. 1968. Oxidative metabolism and aldosterone regulation of sodium transport. In: Regulatory Functions of Biological Membranes. J. Järnefelt, editor. Elsevier, Amsterdam. pp. 177-194.

10. Sharp, G. W. G., and A. Leaf. 1968. Metabolic effects associated with the stimulation of sodium transport by aldosterone. In: Regulatory Function of Biological Membranes. J. Järnefelt, editor. Elsevier, Amsterdam. pp. 195-201.

11. Civan, M. M., O. Kedem, and A. Leaf. 1966. Effect of vasopressin on toad bladder under conditions of zero net sodium transport. Am. J. Physiol. 211: 569-575.

12. Essig, A., and S. R. Caplan. 1968. Energetics of active transport processes. Biophys. J. 8: 1434-1457.

13. Beauwens, R., and Q. Al-Awqati. 1975. Coupling between $\mathrm{H}^{+}$transport and metabolism in turtle urinary bladder. Abstract, 8th Ann. M. Am. Soc. Nephrol., p. 71.

14. Al-Awqati, Q., R. Beauwens, A. Mueller, and P. R. Steinmetz. 1975. Urinary acidification against a gradient: Coupling of transport to metabolism. Clin. Res. 23: 429A. (Abstr.)

15. Onsager, L. 1931. Reciprocal relations in irreversible processes. Phys. Rev. 37: 405-426.

16. Saito, T., A. Essig, and S. R. Caplan. 1973. The effect of aldosterone on the energetics of sodium transport in the frog skin. Biochim. Biophys. Acta. 318: 371-382.

17. Edelman, I. S., R. Bogoroch, and G. A. Porter. 1963. On the mechanism of action of aldosterone on sodium transport: The role of protein synthesis. Proc. Natl. Acad. Sci. U. S. A. 50: 1169-1177.

18. Goodman, D. B. P., J. E. Allen, and H. Rasmussen. 1971. Studies on the mechanisms of action of aldosterone: Hormone-induced changes in lipid metabolism. Biochemistry. 10 : 3825-3831. 